\title{
Cotidianidad en el Caribe colonial, 1590-1620
}

\author{
por \\ Luis Rafael Burset Flores ${ }^{1}$ \\ Universidad Carlos Albizu \\ Centro de Estudios Avanzados de Puerto Rico y el Caribe \\ Universidad del Turabo
}

En la correspondencia oficial de los funcionarios reales de la Corona española a finales del siglo XVI y principios del XVII encontramos referencias a situaciones de vida diaria y a particularidades de los habitantes de la región de lo que se conocerá como la Cuenca del Caribe. Las costumbres, actitudes o actividades diarias que se reportaban estaban recogidas en la referencia a algún evento de relevancia para el gobierno del imperio o de la colonia. Aunque se emiten desde un punto de vista oficialista, éstas nos ayudan a descubrir rasgos distintivos de estos pueblos. Otros aspectos de la cotidianidad son reportados por individuos que participaron en ellos, aunque planteados en función de una solicitud de mercedes. Este ensayo recoge algunos de esos aspectos de la vida diaria en el Caribe reflejados en las descripciones recogidas en la correspondencia con el rey y el Consejo de Indias.

Palabras ClaVe: cotidianidad; Caribe; correspondencia; pueblo; trabajo; tierra adentro; hatos; juego; contrabando; extranjeros; parcialidades.

Cómo citar este artículo / Citation: Burset Flores, Luis Rafael, "Cotidianidad en el Caribe colonial, 1590-1620", Revista de Indias, LXXVIII/274 (Madrid, 2018): 735-756. https://doi.org/10.3989/revindias.2018.022.

Michel de Certeau define cotidianidad como «una manera de hacer» las cosas por parte de la sociedad frente a la vigilancia que les imponen los sistemas gubernativos en el ejercicio del poder $^{2}$. ¿Cuál es la importancia de la cotidianidad? Mary Luz Uribe Fernández sostiene que es dentro de la vida cotidiana en que se construye la realidad, que define como «la vida de todo

1 lrburset@gmail.com, ORCID iD: https://orcid.org/0000-0002-1439-2207.

2 De Certeau, 2000: XLIV. Parte de los conceptos foucaultianos de poder y vigilancia. de uso y distribución Creative Commons Reconocimiento 4.0 Internacional (CC BY 4.0). 
hombre y constituye el centro de la historia», y desarrolla su identidad ${ }^{3}$. Dando importancia a estos dos aspectos, el historiador cubano Jorge Ibarra Cuesta continúa investigando el proceso de formación de las nacionalidades del Caribe hispano desde la perspectiva de la resistencia en el día a día 4 .

La cotidianidad se ocupa de hechos individuales, encontrándose en el extremo opuesto a los llamados eventos «históricos»; por esto, queda atendida por la microhistoria. Sobre la relación entre la historia y la microhistoria, Mario Cancel subraya que «Muchas veces, la Microhistoria rectifica los consensos de la Historia Nacional», y añade que «la Microhistoria y la Microbiografía se mueven por los márgenes, las periferias y la infamia $\rangle^{5}$. Para abordar la microhistoria, se puede recurrir al relato oral, a las crónicas y a los diarios personales ${ }^{6}$. Sin embargo, la misma documentación de archivo de donde surgen los grandes relatos históricos nacionales nos permite un atisbo a la cotidianidad colonial de las últimas décadas del siglo XVI y las primeras del XVII.

En el presente ensayo pretendemos descubrir aspectos de la vida cotidiana en el Caribe colonial ${ }^{7}$ durante las últimas décadas de la hegemonía española sobre la región ${ }^{8}$. Aunque tiende a privilegiar a las clases dominantes, una

3 Uribe Fernández, 2014: 101.

4 Ibarra Cuesta, 2012; 2014.

5 Cancel, 2012.

6 Pasek de Pinto, 2006: 85.

7 Gaztambide, 2003: 47. A pesar de constituir «un poco de tierra y mucha agua», como refiere Gelpí (2013), la documentación de los siglos XVI y XVII consultada para este trabajo refleja la existencia de una conexión entre las islas antillanas y las ciudades costeras de los actuales países de Venezuela, Colombia y Panamá. A pesar de que el caribeñista puertorriqueño Antonio Gaztambide Géigel advierte contra los peligros que representa clasificar a la región, en vista de la gran variedad de definiciones que existen, debemos adoptar para nuestro esbozo la definición de «cuenca del Caribe» o «Gran Caribe» de entre la variedad de definiciones existentes para la región; ésta, además de las islas, incluye las costas de Centro y Sudamérica.

8 Morales Carrión, 1995: 59. Hemos seleccionado este período porque a partir del establecimiento de otras naciones en la región, el Caribe perderá la uniformidad que intentamos descubrir en nuestra investigación. A pesar de que Inglaterra había retado los reclamos de exclusividad sobre la región por parte de España con su doctrina de ocupación efectiva, a principios del siglo XVII se materializaron los primeros intentos de ocupación — no todos exitosos - de varias islas por parte de Inglaterra, Francia y Holanda. Entre éstos, destacamos la de San Eustacio en 1600 por parte de Holanda, Santa Lucía en 1605 y Granada en 1609. Aunque no se oficializó hasta muchos años más tarde, Francia ocupó el espacio noroeste de la isla Española abandonado por España en 1606, hasta convertirlo en su colonia de Saint Domingue, recibiendo el reconocimiento oficial español en 1697 bajo el Tratado de Ryswick. Morales Carrión cataloga como profundo el cambio de condiciones que se experimentó en la 
mirada cuidadosa a la documentación oficial encontrará referencias a la gente común, sus ocupaciones, sus costumbres y sus conflictos, permitiéndonos un atisbo a su vida cotidiana. Desde la óptica oficialista, los funcionarios reales describen un pueblo que constituye una masa anónima de individuos sin orden, honor ni importancia. Es ese pueblo el que De Certeau presenta como la masa que hay que controlar. Sin embargo, Moya Pons lo revalora como sujeto histórico, refiriéndose a él como «el aliento real que ha animado la historia humana»?.

En su análisis sobre la construcción social de la exclusión, Augusto de Venanzi identifica los orígenes etnocéntricos de los discursos y las prácticas excluyentes contra los grupos que son relegados al fondo de las escalas sociales. En la dinámica entre la cultura dominante, sus valores, convenciones y prácticas, y los grupos subordinados, con «subculturas» o culturas oponentes, se excluye a los últimos con una variedad de estrategias, que incluyen el discrimen racial, de clase, de ocupación, entre otros ${ }^{10}$.

$\mathrm{Al}$ abordar el tema de la cotidianidad utilizando la correspondencia oficial, además de las consideraciones anteriores, debemos tener en mente otra igualmente importante. Los funcionarios de la Corona, miembros del estamento dominante y controlador ${ }^{11}$, utilizaron la comunicación con la Corte como una poderosa arma con la cual promovían sus intereses personales, se defendían y anticipaban posibles acusaciones, o atacaban a sus enemigos. Sobre esta correspondencia, autores de la serie Cartas de Cabildos Hispanoamericanos han advertido que en ellas hay «argumentos reales en principio, pero no siempre con ajustada veracidad en sus manifestaciones» ${ }^{12}$.

Debemos señalar que en algunas cartas, los oficiales reales son los protagonistas mismos de diferentes aspectos de la vida cotidiana en las colonias que reseñamos. Este es el caso del gobernador de Trinidad, que se comunica-

región, particularmente en el este. Entre éstos, destaca la reducción en los ataques sistemáticos y la destrucción de establecimientos españoles. Además, surgió un aislamiento entre las islas y la península por las condiciones que afectaron el comercio, particularmente en La Española y en Puerto Rico, donde en las primeras décadas del siglo XVII, coincidiendo con el debilitamiento de España, surgirán las sociedades hateras (ver Silié, 2009).

9 Moya Pons, 1976: 7.

10 De Venanzi, 2005. A pesar de que su estudio se realizó en el ámbito del siglo XX, encontramos su aplicabilidad a las sociedades caribeñas de los siglos XVI y XVII.

11 Navarro García, 1982: 28 y 32. Junto con las instituciones transplantadas desde Castilla y adaptadas en las Indias, los estamentos sociales fueron utilizados para excluir a otros del acceso a las riquezas y al poder. La estamentalidad, un rasgo característico de las estructuras del Antiguo Régimen, aceptaba como hecho natural la desigualdad social de los Hombres.

12 Torres Ramírez, Gil-Bermejo y Vila Vilar, 1979: XXI-XXII. 
ba por escrito con los ingleses con quienes rescataba, y del oidor Francisco Manso de Contreras, quien fuera acusado por otros oficiales reales de irregularidades condenables por la ley. En otros expedientes, como las informaciones del abad de Jamaica, sus situaciones particulares, que incluyen referencias a las condiciones de vida en Jamaica, se presentaron en función de la solicitud de mercedes.

\section{El TRABAJO}

En Historia de América Latina, James Lockhart propone que el concepto social principal en las Indias españolas era el de la jerarquía, donde cada grupo étnico - blancos, africanos e indios - tenía su posición fija. Añade que «el principio general de su construcción era que cuanto más español fuera uno, en cualquier sentido, más alta sería su posición» ${ }^{13}$. De aquí podemos inferir que el criollo trabajador estaba alejado de la capa dominante, y más cerca de las categorías de negro o indio, que quedaban subyugadas a la de los españoles.

El régimen de explotación de la mano de obra esclava, inicialmente indígena en las minas de oro, y luego africana en los ingenios azucareros, dependía de una división de clases y razas, donde el hombre blanco, bien peninsular o criollo, tenía una posición dominante ${ }^{14}$. En 1609, el presidente de la Real Audiencia de Santo Domingo se refirió a un grupo de españoles como «criollos», diferenciándolos de los españoles ${ }^{15}$. Con este término, que Lockhart califica como "apodo derogatorio» ${ }^{16}$, Gómez de Sandoval los asociaba a la tierra y los alejaba de España y del servicio a la Corona. Reportaba que, jun-

13 Lockhart, 1990: 80.

14 Los historiadores del Caribe coinciden en esta clasificación. En el caso de Cuba, Leví Marrero se basa en un padrón de 1582 para colocar a los vecinos que vivían de su trabajo, y sus hijos, por debajo de los «vecinos» en general, pero sobre los estantes, negros horros e indios (Marrero, 1974: 325).

15 No consideramos necesario hablar sobre el concepto de criollismo en las Américas. Sin embargo, Guillermo Céspedes del Castillo presenta propuestas interesantes (Céspedes del Castillo, 1983: 295 y ss.); entre ellas, relaciona directamente la migración predominantemente andaluza y extremeña con la forma de vida en las Indias: «la vida cotidiana, las costumbres, el lenguaje coloquial — tanto en sus aspectos fonéticos como semánticos, en modismos como en metáforas - se hicieron andaluces y extremeños en aquello que no tuvieron de típicamente indiano» (p. 298).

16 Lockhart, 1990: 107. 
to con mulatos y zambaigos ${ }^{17}$, los criollos blancos rehusaban a trabajar y a servir a los españoles. En consecuencia, el trabajo recaía sobre los indios ${ }^{18}$.

Donde el presidente solo plantea el dato, otros miembros de la Audiencia nos presentan una justificación: la adopción de los conceptos de hidalguía y su relación con los trabajos manuales, considerados viles. A pesar de que era muy escasa la población de españoles, los criollos no se querían aplicar al trabajo: «porque es tan introducido por acá el tener esto por afrenta, cuando lo es el vivir pobres y necesitados por no hacerlo» ${ }^{19}$. Sin embargo, en Panamá relacionaban el rechazo al trabajo con la compensación. El oidor Villanueva Zapata refirió en 1595 que los españoles trabajadores se quejaban del poco salario que recibían en relación a lo que ganaban «en tierra buena y poblada»; para contentarlos, «se les da vino y bizcocho y carne y pescado, aceite y vinagre» ${ }^{20}$.

A pesar de las prohibiciones, los extranjeros, objeto de sospechas por parte del gobierno, se encontraban en el grupo trabajador libre. Las actitudes hacia ellos eran muy variadas, según la situación de cada colonia. El gobernador de Puerto Rico solicitaba que se le permitiera componerlos porque, además de trabajar, eran utilizados para la defensa de la Isla. Añadía que «viven de su industria y trabajo, y si éstos se fuesen de la tierra, quedaría sin vecinos, y yo sin gente para poderla defender, y es buena gente» ${ }^{21}$. Bajo estas

17 Real Academia Española de la Lengua. Zambaigo es una de las muchas castas que surgieron y fueron clasificadas en América. Se refiere al hijo de chino (hijo de indio y zambo) e india, siendo el zambo hijo de negro e india.

18 Carta de Diego Gómez de Sandoval, presidente de la Audiencia de Santo Domingo, 20 de agosto de 1609, Archivo General de Indias, Sevilla (AGI), Audiencia de Santo Domingo (SD) 53, ramo (r.) 1, número $\left(\mathrm{n}^{\circ}{ }^{\circ}\right) 27$, folio (f.) 1v: «en estas provincias hay mucha gente española, así de la que de ordinario viene de esos reinos, como de los criollos mulatos y zambaigos, los cuales, con ser personas humildes y pobres, rehúsan el trabajo y mucho más el servir españoles, de que resultan inconvenientes claros, con lo cual se dobla el trabajo a los indios». No es nuestro interés repetir los análisis de los sistemas de producción. Más bien, traer a la atención la desvalorización del trabajo del hombre blanco. Estas apreciaciones contrastan con el dato aceptado de que en las haciendas y estancias de producción para consumo interno (es decir, no para exportación), la mano de obra incluía el trabajo del núcleo familiar (Gelpí, 2000: 41).

${ }_{19}$ Carta de la Audiencia de Santo Domingo, 17 de julio de 1611, AGI, SD 54, r. 2, n. ${ }^{\circ} 71$, f. 1. Esta frase continúa: «porque como para sus labores y granjerías tienen necesidad de negros, y éstos no trabajan la mitad de lo que un peón en España, y cuestan muy caros, y se mueren, es fuerza que estén siempre pobres y con necesidad».

20 Carta del oidor Diego de Villanueva Zapata, 12 de mayo de 1595, AGI, Panamá (PAN) 14 , r. 11, n. $^{\circ} 64$.

21 Carta de Pedro Suárez Coronel, gobernador de Puerto Rico, 14 de febrero de 1595, AGI, SD 155, r. 12, n. ${ }^{\circ} 140$. 
mismas condiciones, en la isla Margarita había dos flamencos: uno servía de trompeta en la casa del gobernador, y otro de carpintero para el apresto de las canoas de la granjería de las perlas ${ }^{22}$. En Cuba, se les describía como «gente pobre, que unos viven de pescar y otros de aserrar maderas y ser carpinteros y oficiales de mano» ${ }^{23}$.

En contraste, Gerónimo de Zuazo, gobernador de Cartagena, pedía que no se permitiese pasar ingenieros extranjeros porque «son voluntariosos y demasiadamente libres, a cuya causa los tienen por sospechosos» ${ }^{24}$. En Santa Marta, la mayoría de los residentes no españoles en 1606 eran portugueses, divididos igualmente entre vecinos y viandantes. Entre los extranjeros se encontraban Joan Angel, «pechelín, soltero, ha que reside en un pueblo de esta gobernación dos meses... es armero»; Estéfano Aparicio, platero borgoñés que hacía cuatro años asistía en la ciudad; y Joan Rut, «alemán, soltero, canoero en la granjería de las perlas, donde ha que reside tres años ${ }^{25}$.

Los extranjeros nutrieron los cuerpos militares. Asociando la falta de aplicación al trabajo con el desorden. En 1592, el licenciado Salazar, oidor de la Real Audiencia de Panamá, recomendó incorporar a la milicia a las personas que habían pasado a las Indias de manera irregular, a pesar de las prohibiciones. En ello habría dos beneficios: los alejaría del vicio y le ahorraría a la Corona el gasto de los soldados que se reclutaban en la península para ser enviados a las Indias ${ }^{26}$.

Sin aparente relación entre la recomendación de uno y la acción de otro, Gómez de Sandoval justificaba en 1610 el que muchas de las personas que habían llegados en barcos de negros o en navíos por vía de Canarias se hu-

22 Carta de Fadrique Cáncer, gobernador de Isla Margarita. 1 de mayo de 1607, AGI, SD 180, r. 5 , n. ${ }^{\circ} 20$, f. 1.

23 Carta de Pedro Valdés, gobernador de La Habana, 15 de diciembre de 1605, AGI, SD 100 , r. 2 , n. ${ }^{\circ} 29$, f. $1 \mathrm{v}$.

24 Carta de Gerónimo de Zuazo, gobernador de Cartagena, 5 de junio de 1601, AGI, Santa Fe (SF) 38, r. 2, n. ${ }^{\circ} 30$, f. 2 v.

25 Carta de Andrés de Salcedo, gobernador de Santa Marta, 20 de diciembre de 1606, AGI, SF 49, r. 14, n. ${ }^{\circ} 60$ y 61. El número 60 incluye un listado con detalles de cada extranjero en la ciudad. El término pechelingue, que tenía variantes, era utilizado para señalar a algunos ingleses.

26 Carta del oidor licenciado Salazar, 3 de mayo de 1591, AGI, PAN 14, r. 7, n. ${ }^{\circ} 34$ f. 1v.: «Suplico a Vuestra Majestad sea servido de mandar que se advierta que las Indias están llenas de gente viciosa y pobre (que son los que suelen desasosegar la república) que han pasado sin orden y asentándose del servicio de las armadas, los cuales les será bien ocuparlos en la guerra; excusarse ha el gasto (que no es pequeño) que se hace con la gente que Vuestra Majestad manda hacer en Castilla, y ocuparse han los que están acá y con el ejercicio olvidarán los inconvenientes que trae la ociosidad». 
biesen convertido en soldados, necesarios para la defensa de la isla y para mantener sus costas limpias de enemigos. Además, así cumplía con el número ideal de plazas militares. Se justificó diciendo que «de otra manera no se puede hacer, así porque los naturales no son inclinados a la guerra, como porque el vicio con que se crían es tan grande que aborrecen todo género de trabajo» ${ }^{27}$.

El negro era la fuerza de trabajo. La Audiencia de Santo Domingo había reportado unos años antes que las negras y mulatas libres se ocupaban de «las costuras y labores de camisas y ropa blanca», mientras que los negros y mulatos libres, y los esclavos jornaleros, eran responsables de «las labores del campo y oficios mecánicos del pueblo» ${ }^{28}$. Es inevitable encontrar la contradicción en los mensajes de los miembros de la Real Audiencia: los mulatos y zambaigos laboraban en los campos, pero no querían trabajar en las ciudades. En contraposición con esta imagen sobre el negro libre, en 1603 el gobernador de Cartagena expresaba admiración por los cimarrones que se habían establecido en una ciénaga. Los describió como «gente muy valiente y suelta, sufridora de trabajos y tan de su parte la tierra por donde andan, que parece que solo la hizo Dios para ellos» ${ }^{29}$.

Sobre el uso de los esclavos, otro presidente de la Real Audiencia de Santo Domingo, Antonio Osorio, nos abre una ventana a la vida doméstica en Santo Domingo. Se quejaba al rey en 1606 de lo que él entendía era un exceso en el número que los vecinos tenían en sus casas. Sobre esto, refería «los que no tienen más caudal que veinte o veinte y cinco esclavos ocupan la mitad de ellos y las veces más era en el servicio de ellas, siendo cosa tan superflua y tan costosa, por tener empleado tanta cantidad en lo que en España se hace con una o dos criadas ${ }^{30}$. Encontramos una justificación para este hábito en Sánchez Albornoz: el número de esclavos en el cuerpo del servicio doméstico realzaba el status social del $\mathrm{amo}^{31}$.

La baja opinión que los oficiales vertían sobre los criollos no se limitaba a los pobres, los negros y los esclavos. En 1604, en Santo Domingo, el fiscal Pedro de Arévalo Sedeño tachaba la preparación del clero criollo, de los frai-

27 Carta de Diego Gómez de Sandoval, presidente de la Audiencia de Santo Domingo, 30 de septiembre de 1610, AGI, SD 54, r. 1, n. ${ }^{\circ}$ 37, f. 1.

28 Carta de la Audiencia de Santo Domingo, 27 de octubre de 1608, AGI, SD 52, r. 8, n. ${ }^{\circ} 138$, f. $1 \mathrm{v}$.

29 Carta de Jerónimo de Zuazo, gobernador de Cartagena, 16 de febrero 1603, AGI, SF 38, r. 2, n. $^{\circ} 48$.

30 Carta de Antonio Osorio, presidente de la Audiencia de Santo Domingo, 12 de octubre de 1606, AGI, SD 52, r. 6, n. ${ }^{\circ} 74$, f. 2 v.

31 Sánchez Albornoz, 1990: 26. 
les y religiosos, señalando que «no son tan observantes como en España y mucho menos lo son los criollos que han nacido en estas tierras y recibido aquí el hábito, porque los que de allá vienen ya profesos son los que sustentan la observancia y son causa que del todo no se olvide la regla, haciendo en esto notable ventaja a los criollos ${ }^{32}$.

\section{LA GENTE DE LA TIERRA ADENTRO}

Fred Bonner afirma que en la América colonial, la ciudad era España ${ }^{33}$. En contraste, «la tierra adentro», era ese otro mundo alejado - y protegidode los centros de poder ${ }^{34}$, que, conceptualmente, sería lo opuesto a la ciudad. Allí se encontraba la mayoría de las personas que pertenecían al fondo de la escala social, y que constituían una especie de masa anónima que sufría de una imagen negativa generalizada por su modo de vida, más laxo de lo que hubieran preferido los funcionarios reales.

Los hatos y las estancias recogían a comunidades mixtas de blancos, mulatos y negros esclavos, de quienes surgiría el campesinado en el Caribe español ${ }^{35}$. La forma de vida giraba en torno a la montería de vacas, de las cuales se tomaba la carne y el cebo, que se utilizaba también para contrabandear ${ }^{36}$. Aprovechaban la distancia física de las capitales para vivir de acuerdo a sus necesidades, explotando oportunidades como las que representaba el contrabando con extranjeros, y libres de las convenciones sociales que regían en los centros de poder. Como señala Moya Pons, «vivían su vida conforme a lo que su naturaleza les mandaba ${ }^{37}$.

En 1604, el Presidente Osorio recibió órdenes de la Corona para desmantelar cuatro pueblos de la llamada Banda Norte de la Isla Española y mudarlos cerca de la ciudad de Santo Domingo. El plan, conocido en la historiogra-

32 Carta de Pedro de Arévalo Sedeño, fiscal de la Audiencia de Santo Domingo, 20 de diciembre de 1604, AGI, SD 52, r. 4, n. ${ }^{\circ} 15$, f. $1 \mathrm{v}$.

33 Bonner, 1986: 22.

34 En Cuba, este espacio se demarcaba con el establecimiento de una distancia concreta con La Habana: cincuenta leguas. Memorial de don Rodrigo de Velasco, gobernador de Cuba, 1618, AGI, SD 100, r. 7, n. ${ }^{\circ} 174$.

35 Sydney Mintz ha escrito sobre el tema del surgimiento del campesinado en el Caribe, proponiendo categorías según la actividad productiva en la que se vieron involucrados. Mintz, 1985: 125-153.

36 Carta de Diego Gómez de Sandoval, presidente de la Audiencia de Santo Domingo, 20 de enero de 1610, AGI, SD 54, r. 1, n. ${ }^{\circ} 1$, f. 1.

37 Moya Pons, 1976: 9. 
fía dominicana como «las devastaciones de Osorio», pretendía acabar el contrabando con extranjeros. Se ejecutó en 1605, y resultó desastroso tanto para la economía como para el control español sobre la Isla y, eventualmente, sobre la región Caribe. Este presidente es un excelente ejemplo de cómo la correspondencia oficial servía para los intereses particulares de su autor.

Osorio desvaloraba abiertamente tanto a la gente como a la propiedad de las regiones que se debían desmantelar. Sobre ellos, declaró que la única barrera que podrían encontrar las despoblaciones era «la gente perdida que hay en esta isla, que como es tan larga, hacen la vida a esta medida, sin temor de justicia divina ni humana» ${ }^{38}$. Dos años después, Osorio volvería a descalificarlos, tildándolos de «hombres baldíos sin oficios y que no sirven y andan baldíos por los... lugares de esta isla..., gente perdida ${ }^{39}$.

Desde el punto de vista material, no se perdería mucho con las mudanzas. Según señaló, las posesiones de estas personas consistían en «algunas sillas y bancos hechos de sus mismas manos de ellos o de sus esclavos, con los cueros de sus vacas, que donde quiera las podrán volver a hacer, porque camas ni mesas ni otros aderezos de los que se usan en España que pudiera embarazar el traerlo por caminos largos no lo tenían, ni entre ellos se usaba». Además, las casas eran de paja, que podrían ser reconstruidas en cualquier otro lugar ${ }^{40}$.

En Nata, los vecinos habían abandonado la vecindad de la ciudad para mudarse a los hatos, donde vivían «miserablemente..., donde excusan vestidos suyos y de sus mujeres e hijos, y aunque a la frecuentación de los sacramentos asisten menos de lo que fuera razón, ellos muestran de esto harto

38 Capítulo de Antonio Osorio, presidente de la Audiencia de Santo Domingo, 15 de diciembre de 1604, AGI, SD 52, r. 4, n. ${ }^{\circ} 10$, f. 1.

39 Carta de Antonio Osorio, presidente de la Audiencia de Santo Domingo, 12 de octubre de 1606, AGI, SD 52, r. 6, n. ${ }^{\circ}$ 73, f. 4 . A pesar de la aportación que podría hacer desde su visión particular de la gente y la vida en La Española en la primera década del siglo XVI. Registro: Isla Española, 1603, AGI, SD 868, libro (en adelante, 1.) 3. También, Carta de Antonio Osorio, que fue presidente de la Audiencia de Santo Domingo, 20 de agosto de 1608, AGI, SD 52, r. 8, n. ${ }^{\circ}$ 122. Carta de Antonio Osorio, presidente de la Audiencia de Santo Domingo, al rey, 10 de octubre 1608, AGI, SD 52, r. 8, n. ${ }^{\circ} 133$, fs. 1, 1v, 3v y 4 . En octubre de 1608, Osorio escribió al rey que había recibido demandas de los afectados por las despoblaciones que montaban más de un millón de ducados por las tierras y ganados que los vecinos perdieron con las mudanzas. Alejándose de las implicaciones, y acercándose al rey, se presentó como «mero ejecutor» de las reducciones. Procuró dejar claro que éstas habían sido «una voluntad determinada de Vuestra Majestad»; hizo un extenso repaso de lo que podríamos llamar el programa de la reducción de los pueblos, con todas sus etapas y beneficios.

40 Carta de Antonio Osorio, presidente de la Audiencia de Santo Domingo, 20 de agosto de 1605, AGI, SD 52, r. 5, n. ${ }^{\circ} 28$, f. 1v. 
sentimiento ${ }^{41}$. Por estas mismas razones, el gobernador de Santa Marta insistía en la necesidad de mantener pueblos donde la gente de los hatos pudiese pasar a oír misa ${ }^{42}$.

El gobernador de Venezuela nos suma elementos al inventario de vicios atribuidos a la gente de la tierra adentro. El vivir sin oficio ni ocupación ya no era suficiente; en aquel lugar no se respetaba la vida. Declaró que «sin ningún temor de Dios ni de Vuestra Majestad ni de su justicia, usan de hierbas perversas que con poco enojo que con uno tengan es fácil matarlo sin que haya habido justicia que lo remedie» ${ }^{43}$.

El deseo de venganza movió en 1601 a Álvaro de Quenda, residente de Montecristi en La Española, a llevar flamencos e ingleses para atacar al doctor Pedro Sanz Morquecho, oidor de la Real Audiencia de Santo Domingo, quien se encontraba visitando la tierra adentro; esto lo haría vulnerable al ataque. Quenda huyó a Jamaica con un grupo de ingleses a quienes servía de lengua y había prometido mil quintales de palo de Brasil. Fueron interceptados por el gobernador de Jamaica, Fernando Melgarejo de Córdoba, y por varios oficiales reales en la bahía de Morante, donde lo emboscaron y arres$\operatorname{taron}^{44}$.

El negro de la tierra adentro se desenvolvía con una libertad que no conocería en las ciudades ${ }^{45}$. El gobernador de Santa Marta reportaba el cambio que habían sufrido los esclavos cuando fueron sacados de las pesquerías de perlas y llevados a la tierra adentro a cortar palo de brasil en 1615. Sobre ellos declaró «los negros están tan ladinos y libres, y sobre sí y habituados a estar en tierra, en el campo, donde no se les encarcela ni castiga con el rigor que se solía hacer con ellos» ${ }^{46}$.

Gómez de Sandoval refería el fenómeno de mayorales, mozos y esclavos de servicio de los hatos, y mencionaba que a ellos acudían muchas mulatas y negras ganaderas y libres «dando ocasión a los mayorales vaqueros mozos y

${ }^{41}$ Carta del presidente Francisco Valverde de Mercado, 23 de mayo de 1609, AGI, PAN 16, r. 1, n. $^{\circ} 4$, f. 10.

42 Carta de Diego de Argote, gobernador de Santa Marta, 21 de junio de 1612, AGI, SF 49 , r. 15, n. $^{\circ} 104$, f. 1.

43 Carta de Alonso Suárez del Castillo, gobernador de Venezuela, 7 de septiembre de 1602, AGI, SD 193, r. 13, n. ${ }^{\circ} 36$, f. $1 \mathrm{v}$.

44 Informaciones: Fernando de Córdoba Melgarejo, 1605, AGI, SD 17, n. ${ }^{\circ}$ 8, fs. 1v y 5.

45 Ibarra Cuesta, 2012: 68.

46 Carta de Diego Fernández de Argote, gobernador de Santa Marta, 19 de junio 1615. AGI, SF 50, r. 1 , n. ${ }^{\circ} 1$, f. 1. 
esclavos que ofendan nuestro Señor y a que hurten ${ }^{47}$ a sus dueños para pagar los excesos que con ellos cometen ${ }^{48}$.

\section{TRANSGRESIONES}

El concubinato, o amancebamiento, ha sido parte de la historia de América. Asunción Lavrin lo clasifica como una costumbre social ${ }^{49}$, mientras César Salcedo Chirinos lo presenta - junto con el mestizaje y el contrabandocomo una realidad contraria al ordenamiento de la vida que suponía la colonización ${ }^{50}$. Descubrimos en la documentación oficial frecuentes acusaciones de amancebamientos, ya no solo contra el pueblo llano, sino contra gobernadores y funcionarios reales.

Los amancebamientos y la manera en que los involucrados resistían los esfuerzos por ponerles fin fueron señalados por el gobernador de Puerto Rico en 1609. En este caso, los imputados no eran negros ni mulatos, sino «hombres principales y de lo más granado de esta ciudad, y muchos del cabildo». Esta situación afectaba tanto a mujeres casadas como a solteras. Los vecinos resistían y resentían los intentos de la Iglesia de ponerle fin a su estado, y por pertenecer al estamento dominante, procuraban «venganza por las vías que pueden, así contra el obispo como contra los demás sacerdotes» ${ }^{51}$.

En Santa Marta, Catalina de los Ángeles fue delatada en 1593 como la manceba del gobernador Francisco Marmolejo ${ }^{52}$. En La Española, la esposa f. $3 \mathrm{v}$.

47 Carta del fiscal Bartolomé Morquecho, 1 de octubre 1609, AGI, PAN 16, r. 1, n. ${ }^{\circ}$ 14,

48 Expediente sobre varios puntos relativos al funcionamiento de la Audiencia de Santo Domingo, 3 de octubre de 1608-11 de julio de 1621, AGI, SD 52, r. 8, n. ${ }^{\circ} 131$, fs. 1-2.

49 Lavrin, 1990: 118.

50 Salcedo Chirinos, 2009: 23. Este ordenamiento abarcaba lo político, económico, social, eclesiástico y sexual. Añade que en una sociedad de clases, a mayor la calidad de los implicados en estos actos, menor la posibilidad de que fueran sancionados por el amancebamiento. Para atender el problema que representaba el amancebamiento para las autoridades coloniales de Puerto Rico en el siglo XVII, éste fue declarado pecado mortal en las Constituciones Sinodales de Puerto Rico de 1645. Santiago Otero y García García, 1986: 123-124, constitución número 153.

51 Carta de Gabriel de Rojas, gobernador de Puerto Rico, 29 de febrero de 1609, AGI, SD 155, r. 16, n. ${ }^{\circ}$ 205. En su estudio sobre el conjunto de islas (Cuba, La Española y Puerto Rico), Ibarra Cuesta refiere que los amancebamientos se concentraban en los campos y poblados alejados del centro del poder. El testimonio presentado demuestra que esta costumbre llegaba hasta la misma ciudad de San Juan. Ibarra Cuesta, 2012: 160.

52 Carta de Francisco Manso de Contreras, gobernador de Santa Marta, 7 de abril de 1593, AGI, SF 49, r. 12, n. ${ }^{\circ} 48$, f. $3 \mathrm{v}$. 
del extranjero Juan de Monpobilla, Juana de Rivera, estaba amancebada con el oidor Gonzalo Mejía de Villalobos. Al no poder ponerle fin a la relación, Monpobilla la abandonó con dos hijas y se fue a Francia, su tierra natal, en un navío francés que tomó en la banda del norte ${ }^{53}$.

Esta situación también involucraba a los extranjeros. La portuguesa María Rodríguez vivía en Cuba, con casa propia, estancia y esclavas. Era casada con un portugués, que hacía cuatro años había salido a Sevilla, desde donde la envió a buscar para hacer vida maridable. Ella se excusaba diciendo que no había quién le comprara su hacienda, sin mucha pérdida, y que su marido la dejó muy empeñada, por lo que ella tenía que ir pagando lo que debía. Tras averiguaciones, se supo que no era pariente de Pedro Francisco, con quien vivía, sino que estaban amancebados, por lo que fueron acusados y él desterrado de la isla, aunque apeló a la Real Audiencia de Santo Domingo ${ }^{54}$.

Aparte del amancebamiento, estos «crímenes» incluían otros de naturaleza sexual, y por parte de funcionarios reales. En los cargos que se le pusieron al oidor de la Real Audiencia de Santo Domingo, Francisco Manso de Contreras, se le descubrió el cobro de perdones por medio de favores sexuales. Tras acusarla por rescates en la villa de Azua, el oidor recibió a María Magdalena, que lo visitó acompañada de Mari Núñez. Finalmente, Manso de Contreras las liberó y no procedió contra María Magdalena, después de haberlas tenido en su aposento y haber pasado la noche con Núñez «para dormir con ella» ${ }^{55}$.

La sodomía, considerada también como crimen, queda registrada en pocas pero interesantes instancias ${ }^{56}$. En Cartagena, en 1595 fue condenado el negro Juan Gerónimo por haber cometido «el pecado nefando» con César de Bartolomé, y Tomás Ximénez, todos forzados de las galeras. Se les dio tormento a los tres y se hicieron diligencias para averiguar, siendo condenados a ser quemados ${ }^{57}$.

53 Testimonio de autos, 1606, AGI, SD 17, n. ${ }^{\circ}$ 12, f. 50.

${ }^{54}$ Carta de Pedro de Valdés, gobernador de La Habana, 12 de agosto de 1607, AGI, SD 100, r. 2 , n. ${ }^{\circ} 57$, f. 1.

55 «Testimonio del estado de la visita que el señor presidente de Santo Domingo por comisión de SM tomó a los licenciados Villalobos y Manso, oidores», Carta de Antonio Osorio, presidente de la Audiencia de Santo Domingo, 25 de marzo de 1607, AGI, SD 52, r. 7, n. ${ }^{\circ} 92$.

56 Amodio, 2012 incluye una interesante exposición de cómo la sodomía fue utilizada para construir alternidad desde las primeras décadas de la Conquista. Emanuele Amodio.

57 «Título de Teniente de gobernador de Cartagena, 4 mayo 1594», Expediente relativo a don Juan de Quincoces, teniente general de Cartagena, 2 de julio de 1600 a 19 de julio de 1601, AGI, SF 38, r. 1, n. ${ }^{\circ} 26$, f. 11. 
Esta situación parece haber sido común entre los forzados. Juan Martín de Marchena, que se hacía llamar Juan Bautista de Tetuán, había sido condenado a servir en las galeras por seis años, siendo recibido en 1586; cumpliría su sentencia el 19 de junio de $1592^{58}$. En 1594 fue encontrado culpable de cometer el «pecado nefando» con Diego Ruiz Mohan; «murió sobre la fragata napolitana yendo por remos a Panamá», pero Ruiz Mohan fue encontrado culpable y condenado a ser quemado, ejecutándose la condena el 13 de abril de ese año ${ }^{59}$.

En Cuba, el gobernador Juan Maldonado Barnuevo refería una situación similar con los sodomitas de la galera capitana en la que, entre otras gentes, había mulatos negros y mestizos. Informaba que había quemado a 46 personas de dos meses a esa parte, «con que se acabó todo lo que se pudo saber». Añadía que habían sido culpados por confesiones de los demás, muchos moros, de la misma galera ${ }^{60}$.

\section{LOS PELIGROS DEL MAR}

El mar era la única conexión que existía entre las colonias, y la península. En ocasiones fue una puerta sin cerrojo que vulneró las defensas en las que las poblaciones se encerraban para protegerse. Morales Carrión califica como caos internacional el período que duró hasta 1625, cuando «los enemigos de España se internaban en esa zona vital para saquear, robar o destruir los primeros establecimientos del imperio» ${ }^{61}$. Los ataques de enemigos de España a las fortalezas, las flotas y las ciudades españolas en el Caribe interrumpieron la vida diaria, y supusieron un precio. En varias ocasiones, entraron a las ciudades para robar y buscar alimentos, pidiendo rescate - que en ocasiones consistía en casabe y carne - para salir de ellas sin quemarlas.

En 1596 tres barcos ingleses entraron en la ciudad de La Vega en Jamaica e hicieron tierra, tomaron la villa y la saquearon. La población española huyó a los montes donde se rancheaba, cada uno con lo que pudo escapar de su

58 «Relación de los forzados de las galeras», Carta de Pedro de Lodeña, gobernador de Cartagena, 29 de agosto de 1591, AGI, SF 37, r. 6, n. ${ }^{\circ} 101$, f. 12.

59 «Título de Teniente de gobernador de Cartagena, 4 mayo 94», Expediente relativo a don Juan de Quincoces, teniente general de Cartagena, 2 de julio de 1600 a 19 de julio de 1601, AGI, SF 38, r. 1, n. ${ }^{\circ} 26$, f. $11 \mathrm{v}$.

60 Carta de Juan Maldonado Barnuevo, gobernador de La Habana, 2 de agosto de 1596, AGI, SD 20, r. 204.

61 Morales Carrión, 1995: 25. Añade que aunque no fueron muy lucrativos, lograron afectar la vida social de las colonias. 
hacienda. A pesar de que inicialmente pudo huir con su casa y pertenecías, tras un ataque al monte donde se encontraba, el abad Márquez de Villalobos tuvo que abandonarlas, siéndole robado todo por los ingleses, incluyendo los lienzos que cubrían su colchón ${ }^{62}$. En 1619 la Casa de la Contratación envió ropa a los vecinos de Santo Tomé de Oruña en Guayana para socorrer a los vecinos que habían sido robados por los enemigos de España ${ }^{63}$.

Los capitanes enemigos actuaron de variadas maneras con los españoles que capturaban en el mar. Algunos les perdonaban la vida, y los dejaban en cualquier isla. Saliendo el 18 de septiembre de 1609 de Santo Domingo para Caracas, la fragata Santa Elena fue atacada en la costa de Puerto Rico por un navío de piratas. En el ataque, Francisco Tostado de la Peña, de familia dominicana y vecino de Caracas, fue muerto por una bala de artillería.

El pirata se conocía como el capitán Manuel, y había tomado otro barco que había salido de Tenerife con vinos para La Española ${ }^{64}$. Manuel abandonó a los tripulantes y pasajeros de la Santa Elena en la isla de San Cristóbal, de donde fueron rescatados por residentes de Puerto Rico ${ }^{65}$. En 1598, Martín González, vecino de Santo Domingo, pasó algunos meses en Jamaica, a donde lo había soltado un francés que lo había tomado en la mar ${ }^{66}$.

La fragata Santa Ana fue tomada por corsarios ingleses frente a la isla Margarita en 1600. Los ingleses llevaron a los pasajeros hasta las Azores, donde los dejaron en una laja que cubría el mar para que se ahogaran. Fray Pedro Bejarano pudo ser rescatado por los habitantes de la isla San Miguel, aunque otros se ahogaron ${ }^{67}$. En 1618 en Trinidad, los capitanes Arias Nieto y Juan Ruiz Monje se enfrentaron al inglés Guatarral [Sir Walter Raleigh] durante su ataque a la ciudad de San Tomé en Guayana y se mantuvieron al lado del gobernador Palomeque cuando fueron embestidos por el inglés, muriendo los tres ${ }^{68}$.

62 Informaciones de Francisco Márquez de Villalobos, 1603, AGI, SD 16, n. ${ }^{\circ}$ 11, f. 38.

63 Testimonio de las mercaderías repartidas a causa del robo en La Guayana. 2 de julio de 1619, AGI, SD 179, r. 4, n. ${ }^{\circ} 84$, f. 9v.

64 "Información sobre haber tomado un navío de franceses en la isla de Puerto Rico...», Carta de Diego Gómez de Sandoval, presidente de la Audiencia de Santo Domingo, 10 de marzo de 1610, AGI, SD 54, r. 1, n. ${ }^{\circ} 8$, fs. 1-2v.

65 «Información sobre haber tomado un navío de franceses en la isla de Puerto Rico...», Carta de Diego Gómez de Sandoval, presidente de la Audiencia de Santo Domingo, 10 de marzo de 1610, AGI, SD 54, r. 1, n. ${ }^{\circ} 8$, fs. 1-2v.

66 Informaciones de Francisco Márquez de Villalobos, 1603, AGI, SD 16, n. ${ }^{\circ}$ 11, f. 59.

67 Informaciones: Alonso Suárez del Castillo, 1580, 1590, 1600, AGI, SD 16, n. ${ }^{\circ}$ 1, fs. 54v y 62.

68 Carta de Juan de Haro, gobernador de Cumaná, 20 de junio de 1618, AGI, SD 187, r. 5, n. $^{\circ} 33$, f. 1 v. 
Las razones para atacar barcos españoles en el Caribe quedaron recogidas en 1610 en un incidente donde el capitán Recharte [¿Richard?] robó un navío que salía de Santo Domingo para Caracas. El inglés tomó la fragata y dejó a los pasajeros en tierra en los Macorices. En conversación con un fraile que viajaba en ella, Recharte le informó que su gente traía «determinación de hacer el daño que pudiesen, diciendo que ya no había paces y que todos trataban de buscar su vida y rescatar en todas las Indias, para cuyo efecto traía mercaderías para 10.000 cueros y fuerza para tomar navíos en qué enviar$\operatorname{los} \gg\rangle^{69}$.

El estado de paz de España con sus enemigos parece haber sido frágil. En 1612 el presidente Gómez de Sandoval reportaba el ataque de unos navíos franceses a los suyos cerca de la costa de Cabo Rojo en Puerto Rico. Sobre los tratados de paz entre España y sus enemigos, el presidente expresaba «doy cuenta a Vuestra Majestad de esto para que vea cuánto importa la asistencia de estos navíos y presidio en esta isla, y cuán mal cumplen los franceses con las paces asentadas y juradas por su rey» ${ }^{70}$.

\section{ENEMigos DE EspaÑA, AMigos DEL PUEBLO}

La contraparte de las agresiones extranjeras a las colonias fue el contrabando con sus pobladores. Algunos autores matizan esta actividad como actos de resistencia al monopolio comercial impuesto por España a las colonias americanas $^{71}$. En coincidencia o no, en 1605 el gobernador de Jamaica presentaba una razón muy sencilla: una de las causas para el contrabando era el precio excesivo de la vestimenta que llegaba de España, cuando los precios del comercio con extranjeros era mucho menor ${ }^{72}$.

En 1601, el gobernador de La Habana, Pedro de Valdés, presentaba un cuadro alarmante en relación a los rescates, que se realizaban por las bandas del norte y del sur de la Isla. Al no contar con navíos de guerra para combatirlos, había varias naves francesas con 13.000 o 14.000 cueros, invernando

69 Carta de Diego Gómez de Sandoval, presidente de la Audiencia de Santo Domingo, 6 de junio de 1610, AGI, SD 54, r. 1, n. ${ }^{\circ}$ 20, f. 1v. El inglés declaró que era de Plemua [Plymouth] y hacía tres años que residía en Argel y venía con el turco. Había hecho su viaje por la isla de Trinidad, donde quedaban rescatandos como él lo había hecho otros 20 navíos.

70 Carta de Diego Gómez de Sandoval, presidente de la Audiencia de Santo Domingo, 31 de agosto de 1612, AGI, SD 54, r. 3, n. ${ }^{\circ}$ 96, f. 1v. Debió referirse al Tratado de Vervins de 1598, por el que Francis y España firmaban la paz.

71 Destacamos los siguientes trabajos: Deive (1996), Peña Batlle (1988) y Marrero (1974).

72 Informaciones: Fernando de Córdoba Melgarejo, 1605, AGI, SD 17, n. ${ }^{\circ}$ 8, fs. 1 y 2. 
en sus costas, «como si estuviesen en sus casas» ${ }^{73}$. El gobernador de Cumaná refería al rey la normalidad de comunicación entre los extranjeros y los vecinos de la ciudad ${ }^{74}$. El de Margarita declaraba que era tan común el contrabando que «son pocos los que en esta isla se escapan de esto» ${ }^{75}$.

Para poner fin a esta situación, el Consejo de Indias consideró eliminar los puntos de encuentro entre extranjeros y españoles. En el caso de las salinas de Araya, se consideró anegar la salina para evitar la entrada de extranjeros ${ }^{76}$. La reducción de las poblaciones de la banda norte de la isla de La Española en 1605 fue encargada dos años antes de forma conjunta a don Antonio Osorio, presidente de la Real Audiencia de Santo Domingo y capitán general y gobernador de La Española, y al obispo de Santo Domingo, fray Agustín Dávila Padilla ${ }^{77}$. Osorio recomendaría la misma medicina para acabar con los rescates en Cuba, lo que no se ejecutó.

Las declaraciones que se tomaban a piratas, corsarios y a los mismos rescatadores nos arrojan una luz fresca sobre este tema familiar. Nos revelan que a pesar del monopolio, el proteccionismo comercial oficial y las prohibiciones, los moradores de la tierra adentro y algunos oficiales reales eran receptivos a los avances comerciales de estos enemigos de la Corona española. En 1611, el dueño y maestre de fragata, Agustín de Brito, narró la ruta de contrabando que siguió el navío inglés que lo capturó y llevó a bordo. En su testimonio revela la aparente cooperación entre los enemigos de España, quienes corrían de un extremo al otro por las aguas del Caribe, y rescataban en las colonias españolas unas nacionalidades junto a las otras sin aparente conflicto entre si $^{78}$.

73 Carta de don Pedro Valdés, gobernador de La Habana, 25 de septiembre de 1602, SD 100 , r. 2 , n. ${ }^{\circ} 14$, fs. $4 \mathrm{v}-5$.

74 Carta del gobernador Diego Suárez de Amaya, 2 de julio de 1600, AGI, SD 187, r. 3, n. ${ }^{\circ} 3$, f. 1.

75 Carta de Fadrique Cáncer, gobernador de Margarita, 24 de julio de 1601, AGI, SD 180 , r. 4, n. $^{\circ} 15$, f. $1 \mathrm{v}$.

${ }^{76}$ Expediente sobre anegar las salinas de Araya y evitar la entrada de extranjeros, 10 de julio de 1601. AGI, SD 187, r. 3, n. ${ }^{\circ} 8$.

77 Registro: Isla Española, 1603, AGI, SD 868, 1. 3.

78 Carta de Diego Gómez de Sandoval, presidente de la Audiencia de Santo Domingo, 29 de mayo de 1611, AGI, SD 54, r. 2, n. ${ }^{\circ} 49$, fs. 1-1v: «A los 21 de junio descubrieron otro navío y una fragata entre Ocoa y La Beata que iba dándoles caza, y habiéndoles alcanzado al anochecer pelearon con él hasta que la oscuridad de la noche y el tiempo los apartó. Y que prosiguiendo su viaje, llegaron al puerto de la Sabana, que es en el Cabo de Tiburón, por la banda del sur, y allí surgieron para aderezar su navío de los balazos que llevaba, a donde hallaron otros dos, el uno inglés y el otro flamenco, los cuales rescataron carne y cueros, pero no supo con quién porque le pusieron debajo de cubierta, ni más de que era gente ladina, y 
A pesar de los numerosos intentos por poner fin a los rescates en La Española, intentos entre los que se encuentra el proyecto de movilizar y relocalizar a todos los pobladores de cuatro pueblos o villas de la banda norte con todos sus ganados, conocido como las Devastaciones de Osorio, ya mencionadas, el contrabando continuó después de 1605. Se creó una armada para vigilar las costas de la isla Española, armada que se puso a cargo del hijo del presidente de la Real Audiencia. Esta tuvo algún éxito en capturar piratas. Uno de ellos fue Tomás Curi, quien ofreció interesantes testimonios sobre sus «clientes» en las islas, particularmente en Trinidad.

El contrabando llegaba hasta los mismos quilombos de cimarrones de La Española. Según el francés Pereyra, «Los negros rescataban con ingleses y flamencos carne salada y cueros a cambio de mosquetes, pólvora, balas, cuerda, lanzas y desjarretaderas, ruan, paño cañamazo, cuchillos, hilo y 23 negros bozales $\gg{ }^{79}$.

Entre los objetos encontrados en su barco había cartas y billetes firmados por los vecinos de la mencionada isla, que demuestran la confianza y comunicación que había entre los españoles de las islas y los piratas, declarados enemigos de la Corona. Uno de estos billetes, firmado por el teniente de gobernador de La Trinidad, planteaba al capitán inglés, de manera muy cordial, las consecuencias de la decisión de devolver una piragua que llevó sin licencia. En una amenaza, nada solapada, el gobernador advierte que «si no me da la hacienda que estaba en la piragua, no tiene que aguardarle en el puerto sino irse y no volver a él en su vida, porque no se echará buen trato ni le dejarán tomar tierra, agua ni leña». Así, el inglés no tendría más tabaco, que era el modo de pago, además de cañafístula. Por el contrario, si la devolvía, «me tendrá por amigo, y a todos mis compañeros, y tendrá trato todo el tiempo que quisiere y será bienvenido y se le pagará lo que le deben en el pueblo» ${ }^{80}$.

que los ingleses a quien preguntó qué población era aquella le dijeron que los que estaban en ella tenían armas de artillería y municiones, y habiendo estado allí 17 días, hicieron su viaje por el canal de la Bahama a La Trinidad, a donde hallaron tres navíos flamencos y dentro de pocos días llegaron otros muchos, y habiendo rescatado el capitán inglés del navío en que había ido con el gobernador don Hernando de Berrio cantidad de tabaco por mercadurías, se había ido la vuelta de su tierra, dejándole y en su compañía a Guillermo Pereyra, francés, y volviéndole su fragata en la cual fue a Cumaná y a La Margarita, y de allí a este puerto [Santo Domingo] con pescado».

79 Ibidem, fs. 2-2v.

80 «Auto sobre los papeles y billetes que se encontraron en el barco del capitán inglés Tomás Curi», Carta de Diego Gómez de Sandoval, presidente de la Audiencia de Santo Domingo, 15 de julio de 1611, AGI, SD 54, r. 2, n. ${ }^{\circ} 62$, fs. $1 \mathrm{v}-2$ y $4 \mathrm{v}$. 
A manera de cierre, una de las razones que tenían los españoles para visitar los barcos enemigos con los que contrataban era recibir servicios médicos. En la declaración que se tomó a Tomás Curri, capitán del barco con el que se realizaron las transacciones antes mencionadas, éste destacó que Gómez Hernández había llevado y dejado a un hijo para que el cirujano que traía en el barco lo tratara de una enfermedad que padecía ${ }^{81}$.

La comunicación continua con cartas y argumentos de parte y parte, refleja un intenso y extenso proceso de negociación entre los oficiales reales de las islas y los ingleses que pasaban a comerciar ilegalmente con ellos. Nos quedan documentadas las relaciones que sostenían los extranjeros con la gente «baldía» al igual que con altos funcionarios de la Corona. En una región rodeada por el mar, el pueblo reflejaba apertura al extranjero, y poco apego a las leyes coloniales.

A través de esta investigación, hemos intentado capturar algunos aspectos de la cotidianidad en el Caribe español a finales del siglo XVI y principios del XVI ${ }^{82}$. Utilizando la correspondencia de los funcionarios a cargo de las colonias como fuente primaria, recordamos la advertencia de Aníbal Quijano en cuanto a que la mirada del conquistador construye la mirada del «otro» desde una perspectiva de posesión y poder ${ }^{83}$. Entre los prejuicios y el descartar las diferencias, encontramos, no obstante, rasgos particulares de una forma de vida propia del Caribe, de su cotidianidad.

Concretamente, hemos cubierto referencias a la actitud hacia el trabajo, planteada como vagancia, siendo, posiblemente, manifestaciones de resistencia de un pueblo con creciente conciencia de su identidad contra el sistema imperial. Reportamos las características destacadas de la gente de la llamada tierra adentro, germen del campesinado caribeño. Donde Ibarra Cuesta lee resistencia, nosotros retratamos, además, elementos del diario vivir.

81 «Despachos sobre los rescates de La Trinidad y comprobaciones que se hicieron de algunos billetes originales con el capitán Tomás Curri, inglés, de vecinos de La Trinidad. Van asimismo otras declaraciones de algunos flamencos que se sacaron», Carta de Diego Gómez de Sandoval, presidente de la Audiencia de Santo Domingo, 15 de julio de 1611, AGI, SD 54, r. 2, n. $^{\circ} 62$, f. 1 .

82 Morales Carrión, 1995: 60. Afirma que «después de 1625, se produjo un cambio profundo en las condiciones que habían prevalecido en la parte este del Caribe. Colonos no-hispánicos gradualmente poblaron la cadena de islas que se extiende desde Puerto Rico hasta Trinidad». Así, España perdió su hegemonía sobre la totalidad del Caribe. Más adelante, colonos franceses ocuparán los espacios abandonados por los españoles en la isla Española y la isla Tortuga, penetrando permanentemente en las Antillas Mayores.

83 Rivera Pagán, 2013: 48. 
Leímos sobre las realidades sociales que provocaban la condena de la Iglesia, y que no eran otra cosa que simples manifestaciones de la condición humana. Conocimos los peligros que representaba el mar, único medio de comunicación entre las colonias caribeñas, por la exposición de sus habitantes a los ataques de extranjeros. Finalmente, reconocimos el rol dual de los piratas y corsarios extranjeros que, aunque enemigos declarados de España, fueron una importante coyuntura que proveyó de mercaderías a los habitantes, mercaderías que de otra forma, no podrían conseguir.

Las referencias en los documentos oficiales nos permiten atisbar el surgimiento de un pueblo a golpes del aislamiento que sufrieron paulatinamente las colonias del control y de la influencia de la metrópoli, junto a su realidad ante los peligros y las oportunidades del mar abierto. Así, aunque imperfectamente, con la combinación de hechos cotidianos y las apreciaciones oficiales, recogemos un reflejo de los modos de vida en la América temprana en las últimas décadas de la hegemonía de España sobre la región del Caribe. Aquí conocemos a algunos de los individuos que Moya Pons calificaría como «actores que se desenvuelven en los márgenes de nuestra visión acostumbra$\mathrm{da}$, en los intersticios económicos, sociales, culturales y territoriales» de un país, de una región ${ }^{84}$.

\section{REFERENCIAS BIBLIOGRÁFICAS}

Amodio, Emanuele, "El detestable pecado nefando. Diversidad sexual y control inquisitorial en Venezuela durante el siglo XVIII", Nuevo Mundo, Mundos Nuevos, 2012, https://nuevomundo.revues.org/63177, capturado el 1 de julio de 2016.

Andújar, Carlos, Identidad cultura y religiosidad popular, Santo Domingo, Editorial Letra Gráfica, 2007.

Bonner, Fred, "Urban Society in Colonial Spanish America: Research Trends", Latin America Research Review, 21/1 (Durham, 1986): 7-72.

Cancel, Mario, Historiografia: la invención de la memoria. Bitácora de teoría de la historia, 3 de noviembre de 2012, https://mariocancel.wordpress.com/tag/ metodologia-historiografica/, capturado el 10 de octubre de 2015.

Céspedes del Castillo, Guillermo, América Hispánica, 1492-1898, Barcelona, Editorial Labor, 1983.

De Certeau, Michel, La invención de lo cotidiano. Vol. 1, Artes de hacer, México, Universidad Iberoamericana, 2000, reimpresión.

84 Moya Pons, 2009: 20. 
De Venanzi, Augusto, "Outcasts: The Social Construction of Exclusion", Revista Venezolana de Análisis de Coyuntura, XI/2 (Caracas, jul-dic 2005): 117-137.

Deive, Carlos Esteban, Tangomangos. Contrabando y piratería en Santo Domingo, 1522-1606, Santo Domingo, Fundación Cultural Dominicana, 1996.

Gaztambide, Antonio, "La invención del Caribe a partir de 1898 (las definiciones del Caribe, revisitadas)", Tierra Firme, XXI/82 (Caracas, abril-junio 2003), http://www2.scielo.org.ve/scielo.php?script=sci_arttext\&pid=S0798$29682003000200004 \& \operatorname{lng}=$ es\&nrm=i, capturado el 7 de noviembre de 2015.

Gaztambide Géigel, Antonio y Hernández, Rafael (coords.), Cultura, sociedad y cooperación. Ensayos sobre la sociedad civil del Gran Caribe, La Habana/San Juan, Centro de Investigación y Desarrollo de la Cultura Cubana/Proyecto Atlantea de la Universidad de Puerto Rico, 2003.

Gelpí Baíz, Elsa, Los hombres de la Plaza Mayor. Estructuras de Poder en el Puerto Rico del Quinientos, Ponencia presentada durante el Primer Encuentro de Historiadores de Puerto Rico, Puerto Rico, Universidad de Puerto Rico, Recinto de Río Piedras, 1990.

Gelpí Baíz, Elsa, Siglo en blanco, estudio de la economía azucarera, siglo XVI, Río Piedras, Editorial de la Universidad de Puerto Rico, 2000.

Gelpí Baíz, Elsa, "Entrelazando familias. Las familias de Santo domingo y San Juan: sus relaciones de parentesco en el Quinientos", Luis R. Burset (ed.), Actas del Simposio Caribeño de Genealogía e Historia, vol. I, San Juan, Sociedad Puertorriqueña de Genealogía, 2013: 55-70.

Ibarra Cuesta, Jorge, De súbditos a ciudadanos, siglos XVII-XIX. El proceso de formación de las comunidades criollas del Caribe hispánico (Cuba, Puerto Rico y Santo Domingo), tomo I, Santo Domingo, Archivo General de la Nación, 2012.

Ibarra Cuesta, Jorge, De súbditos a ciudadanos, siglos XVII-XIX. El proceso de formación de las comunidades criollas del Caribe hispánico (Cuba, Puerto Rico y Santo Domingo), tomo II, Santo Domingo, Archivo General de la Nación, 2014.

Lavrin, Asunción, "La mujer en la sociedad colonial hispanoamericana", Leslie Bethell (ed.), Historia de América Latina. Tomo 4. América Latina colonial: población, sociedad y cultura, Barcelona, Editorial Crítica, 1990: 109-137.

Lockhart, James, "Organización y cambio social en la América española colonial", Leslie Bethell (ed.), Historia de América Latina. Tomo 4. América Latina colonial: población, sociedad y cultura, Barcelona, Editorial Crítica, 1990: 63-108.

Marrero, Leví, Cuba: economía y sociedad, Tomo 2, siglo XVI: la economía, Madrid, Editorial Playor, 1974.

Mintz, Sidney W., "From Plantations to Peasantries", Sidney W. Mintz y Sally Price (eds.), Caribbean Contours, Baltimore, Johns Hopkins University Press, 1985: 127-153. 
Morales Carrión, Arturo, Puerto Rico y la lucha por la hegemonía en el Caribe. Colonialismo y contrabando, siglos XVI-XVIII, San Juan, Centro de Investigaciones Históricas y Editorial de la Universidad de Puerto Rico, 1995.

Moya Pons, Frank (ed.), La vida escandalosa en Santo Domingo en los siglos XVII y XVIII, Santiago de los Caballeros, Universidad Católica Madre y Maestra, 1976.

Moya Pons, Frank, La otra historia dominicana, Santo Domingo, Librería La Trinitaria, 2009.

Navarro García, Luis, "Honra, pobreza y aislamiento de los oidores indianos", Temas americanistas, 1 (Sevilla, 1982): 31-42.

Pasek de Pinto, Eva, “¿Cómo construir categorías en Microhistoria?", Revista de Artes y Humanidades UNICA, 7/16 (Caracas, 2006): 85-97.

Peña Batlle, Manuel Arturo, La isla de la Tortuga. Plaza de armas, refugio y seminario de los enemigos de España en Indias, Santo Domingo, Editora Taller, 1988.

Rivera Pagán, Luis, Ensayos teológicos desde el Caribe, San Juan, Ediciones Callejón, 2013.

Rodríguez Morel, Genaro, Cartas del Cabildo de la Ciudad de Santo Domingo en el siglo XVII, Santo Domingo, Archivo General de la Nación y Academia Dominicana de la Historia, 2007.

Salcedo Chirinos, César Augusto, "Entre el delito y el pecado: la representación de la sodomía en el Puerto Rico del siglo XIX", Norma Valle Ferrer (ed.), Identidades, VI/7 (Cayey, octubre 2009): 11-34.

Sánchez-Albornoz, Nicolás, "La población de la América colonial española", Leslie Bethell (ed.), Historia de América Latina. Tomo 4. América Latina colonial: población, sociedad y cultura, Barcelona, Editorial Crítica, 1990: 15-38.

Santiago-Otero, Horacio y García García, Antonio (dirs.), Sínodos Americanos. 4. Sinodo de San Juan de Puerto Rico de 1645, Madrid/Salamanca, Centro de Estudios Históricos del CSIC/Instituto de historia de la Teología Española de la UPS, 1986.

Silié, Rubén, Economía, esclavitud y población. Ensayo de interpretación histórica del Santo Domingo español en el siglo XVIII, Santo Domingo, Academia Dominicana de la Historia, 2009.

Torres Ramírez, Bibiano, Gil-Bermejo, Juana y Vila Vilar, Enriqueta, Cartas de Cabildos Hispanoamericanos. Audiencia de Panamá, Sevilla, Escuela de Estudios Hispano-americanos, Consejo Superior de Investigaciones Científicas, 1979.

Uribe Fernández, Mary Luz, "La vida cotidiana como espacio de construcción social”, Procesos Históricos, 25 (Bogotá, 2014): 100-113.

Fecha de recepción: 13 de mayo de 2016.

Fecha de aceptación: 27 de mayo de 2016. 


\section{Everyday life in the Caribbean during Colonial Times, $1590-1620$}

The correspondence between Spanish Crown officials in the Antilles and the Court at the turn of the seventeenth century contains valuable references to everyday events and specific characteristics of settlers in what would come to be known as the Caribbean Basin. Local customs, habits or daily activities were sometimes included in reports on events of relevance to government. While issued from an official point of view, such references help us discover distinctive traits of everyday life in the Caribbean. Other aspects can be gleaned from letters written by individuals, most of which are seeking alms. This essay highlights specific aspects of everyday life in the Caribbean reflected in the descriptions provided in correspondence between the King and the Council of the Indies.

KeY words: Everyday life; Caribbean; correspondence; labour; inland; hatos; gambling; contraband; bias; foreigners. 